\title{
O-Functionalised NHC Ligands for Efficient Nickel-catalysed C-O Hydrosilylation
}

\author{
Simone Bertini and Martin Albrecht*
}

\begin{abstract}
A series of $\mathrm{C}, \mathrm{O}-$ bidentate chelating mesoionic carbene nickel(II) complexes $\left[\mathrm{Ni}(\mathrm{NHC} \wedge \mathrm{PhO})_{2}\right](\mathrm{NHC}=$ imidazolylidene or triazolylidene) were applied for hydrosilylation of carbonyl groups. The catalytic system is selective towards aldehyde reduction and tolerant to electron-donating and -withdrawing group substituents. Stoichiometric experiments in the presence of different silanes lends support to a metal-ligand cooperative activation of the $\mathrm{Si}-\mathrm{H}$ bond. Catalytic performance of the nickel complexes is dependent on the triazolylidene substituents. Butyl-substituted triazolylidene ligands impart turnover numbers up to 7,400 and turnover frequencies of almost $30,000 \mathrm{~h}^{-1}$, identifying this complex as one of the best-performing nickel catalysts for hydrosilylation and demonstrating the outstanding potential of $\mathrm{O}$-functionalised $\mathrm{NHC}$ ligands in combination with first-row transition metals.
\end{abstract}

Keywords: NHC ligands · Nickel catalysis

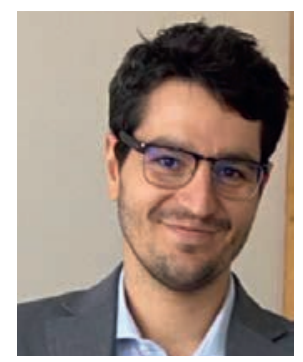

Simone Bertini received his BSc and MSc in Chemistry from the University of Rome TorVergata. In 2016 he moved to Switzerland for his doctoral studies in the group of Prof. Albrecht, where he earned his $\mathrm{PhD}$ as a early stage researcher (ESR) for the Marie Sklodowska-Curie Initial Training Network Non-Noble Metal Catalysis (NoNoMeCat). His research focus is the synthesis, characterization and catalytic applications of firstrow transition metal complexes bearing strong donor ligands such as (mesoionic) $\mathrm{N}$-heterocyclic carbenes.

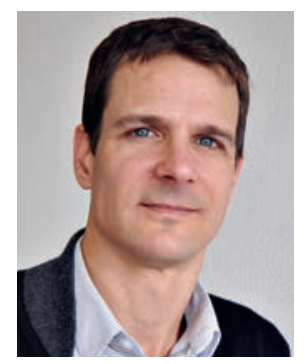

Martin Albrecht studied Chemistry in Bern and graduated with Gerard van Koten at Utrecht University (NL) in 2000. After postdoctoral work with Bob Crabtree at Yale and with Ciba SC (Basel), he started independent research as an Alfred Werner Assistant Professor in Fribourg, then joined the faculty at University College Dublin and returned in 2015 to his alma mater. His research revolves around the ligand-induced control and expansion of the reactivity of metal centres, particularly for catalytic applications. He is fascinated by new ligand classes such as mesoionic $N$-heterocyclic carbenes, and recently also by their $N$-donor analogues.

\section{Introduction}

The use of chelating ligands has become an established methodology for the development of homogeneous catalysts with long lifetime. ${ }^{[1]}$ This concept has also been implemented to $\mathrm{N}$-heterocyclic carbene (NHC) complexes, which is facilitated by the synthetic versatility and easy accessibility of NHC scaffolds. [2] Introduction of chelating sites has been successfully employed to tailor properties of the metal centre such as coordination geometry, electron density, and stability of the metal-carbon bond. Among the countless possibilities for NHC functional-

isation, a popular approach constitutes the implementation of $\mathrm{N}$-donor groups. ${ }^{[3]}$ Less common is the introduction of $O$-donor sites, ${ }^{[4]}$ despite the attractiveness of this type of donors for selected applications. For example, oxygen sites are fundamental for hydrogen bonding. ${ }^{[5]}$ In addition, this functionalisation is key for stabilising typically oxophilic first-row transition metals for catalytic applications, one of the major challenges for developing sustainable catalysts based on Earth-abundant metals. ${ }^{[6]}$ In the absence of chelating stabilization, the $\mathrm{M}-\mathrm{C}_{\mathrm{NHC}}$ bond is generally unstable and limits the catalytic application. This instability was demonstrated to be a key issue for the application of triazolylidene-based mesoionic NHC nickel complexes in Suzuki-cross coupling, which takes place with high initial turnover frequencies but rapidly stalls due to $\mathrm{Ni}-\mathrm{C}$ bond cleavage and ensuing catalyst degradation. ${ }^{[7]}$ We have therefore become interested in enhancing the stability of these complexes by ligand functionalisation and have developed a new class of $O$-donor substituted NHC ligands based on the imdazole, ${ }^{[8]}$ as well as the triazole scaffold. Nickelation under mild conditions afforded the bis-carbene nickel(II) complexes 1a-c, 2 (Fig. 1). ${ }^{[9]}$ Here, these complexes were investigated as precursors for the catalytic hydrosilylation of carbonyl groups, providing one of the fastest and most robust nickel-based catalytic systems known to date. ${ }^{[10,11]}$

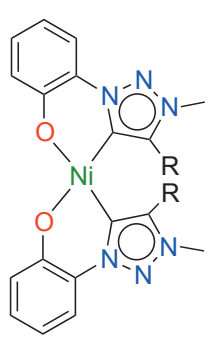

$\mathrm{R}: \mathrm{Ph} 1 \mathrm{a}$ R: Bu 1b

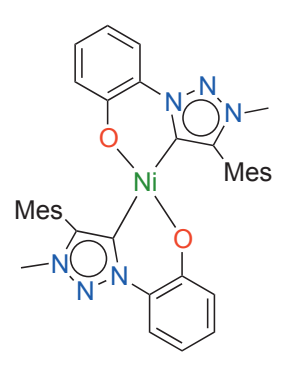

1c

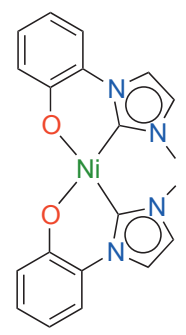

2

${ }^{\star}$ Correspondence: Prof. M. Albrecht, E-mail: martin.albrecht@dcb.unibe.ch

Departement für Chemie und Biochemie, Universität Bern, Freiestrasse 3, CH-3012 Bern, Switzerland 


\section{Results and Discussion}

Hydrosilylation with complexes $\mathbf{1 a}-\mathbf{c}$ and $\mathbf{2}$ was initially probed at a $2 \mathrm{~mol} \%$ catalyst loading using 4-methylbenzaldehyde as model substrate and phenylsilane as hydrosilylation agent. The reaction proceeded to completion with complex $\mathbf{1 b}$ in 1,2-dichloroethane, affording 4-methylbenzyloxysilane in $99 \%$ within $30 \mathrm{~h}$ (entry 1, Table 1). Since hydrosilylation with $\mathrm{PhSiH}_{3}$ afforded mixtures of products, this mixture was subsequently treated with methanolic $\mathrm{NaOH}(1 \mathrm{M})$ for $16 \mathrm{~h}$ to generate the corresponding alcohol. Analysis of this alcohol provided the actual product yield for each reaction. Increasing the temperature to $40{ }^{\circ} \mathrm{C}$ resulted in considerably enhanced activity, affording the product quantitatively in $30 \mathrm{~min}$ (entry 2). Replacing phenylsilane by diphenylsilane or triethylsilane under otherwise identical conditions gave only very slow or negligible substrate conversion (entries 3 and 4). Changing the solvent from dichloroethane to THF considerably lowered the catalytic performance (entry 5), whereas conducting the reaction in dichloromethane affected the reaction only slightly (entry 6). A blank experiment under the same conditions but in absence of the nickel catalyst revealed no detectable activity even over extended reaction time (entry 7), thus confirming the catalytic role of the nickel species.

Table 1. Hydrosilylation of 4-methylbenzaldhehyde with complex $\mathbf{1 b} .^{2}$<smiles>Cc1ccc(C=O)cc1</smiles>
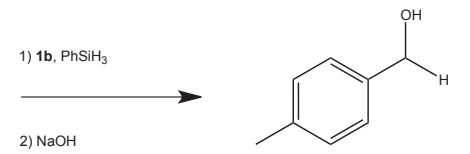

\begin{tabular}{|l|l|l|l|l|l|l|}
\hline entry & solvent & silane & $\begin{array}{l}\mathbf{T} \\
{\left[{ }^{\circ} \mathbf{C}\right]}\end{array}$ & $\begin{array}{l}\text { time } \\
{[\mathbf{m i n}]}\end{array}$ & $\begin{array}{l}\text { conv } \\
{[\%]^{\mathbf{b}}}\end{array}$ & $\begin{array}{c}\text { yield } \\
{[\%]^{\mathbf{c}}}\end{array}$ \\
\hline 1 & $\mathrm{C}_{2} \mathrm{H}_{4} \mathrm{Cl}_{2}$ & $\mathrm{PhSiH}_{3}$ & 25 & 1,800 & 99 & 97 \\
\hline 2 & $\mathrm{C}_{2} \mathrm{H}_{4} \mathrm{Cl}_{2}$ & $\mathrm{PhSiH}_{3}$ & 40 & 30 & 99 & 96 \\
\hline 3 & $\mathrm{C}_{2} \mathrm{H}_{4} \mathrm{Cl}_{2}$ & $\mathrm{Ph}_{2} \mathrm{SiH}_{2}$ & 40 & 60 & 14 & \\
\hline 4 & $\mathrm{C}_{2} \mathrm{H}_{4} \mathrm{Cl}_{2}$ & $\mathrm{Et}_{3} \mathrm{SiH}_{4}$ & 40 & 60 & $<1$ & \\
\hline 5 & $\mathrm{THF}$ & $\mathrm{PhSiH}_{3}$ & 40 & 60 & 73 & 68 \\
\hline 6 & $\mathrm{CH}_{2} \mathrm{Cl}_{2}$ & $\mathrm{PhSiH}_{3}$ & 40 & 30 & 84 & 76 \\
\hline $7^{\mathrm{d}}$ & $\mathrm{C}_{2} \mathrm{H}_{4} \mathrm{Cl}_{2}$ & $\mathrm{PhSiH}_{3}$ & 40 & 60 & $<1$ & \\
\hline
\end{tabular}

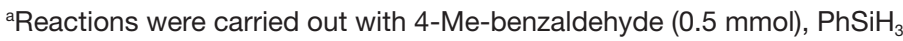
$(0.6 \mathrm{mmol})$ and complex $\mathbf{1 b}(2 \mathrm{~mol} \%)$ in the corresponding solvent $(0.4 \mathrm{~mL})$ with $\mathrm{C}_{6} \mathrm{Me}_{6}(0.05 \mathrm{mmol})$ as internal standard; ${ }^{\mathrm{b}}$ conversion determined by $1 \mathrm{H}$ NMR spectroscopy; ' ${ }^{2}$ yield determined by $1 \mathrm{H}$ NMR spectroscopy after treatment with $\mathrm{NaOH}(1 \mathrm{M})$ in $\mathrm{MeOH}$; ${ }^{d}$ reaction performed in the absence of $\mathbf{1 b}$ (blank run).

Based on these results, the activity of catalysts $1 \mathbf{1 a}-\mathbf{c}$ and $\mathbf{2}$ were compared with the model substrate 4-methylbenzaldehyde under the best conditions (phenylsilane, dichloroethane, $40^{\circ} \mathrm{C}$ ). All complexes reached full conversion in less than $3 \mathrm{~h}$ (Table 2 , Fig. 2) and show similar time-conversion profiles with high reaction rates with $80-90 \%$ conversions. Different C4 substituents on the triazolylidene complexes affected the activity of the metal complexes and the activity is consistent with the electron density on the metal centre as imparted by the ligand, with triazolylidene ligands in 1a-c more donating than imidazolylidene in complex 2 (entries 1-4). Within the triazolylidene series, alkyl groups impart higher electron density than mesityl groups, consistent with a higher activity of complex $\mathbf{1 b}$ vs. $\mathbf{1 c}$ and complex $\mathbf{1 a}$ with a phenyl substituent displaying lowest activity of the triazolylidene complexes. We note that the complex configuration has no obvi- ous relevance and both the trans configured complex 1c as well as the cis isomers $(\mathbf{1 a}, \mathbf{b})$ show catalytic performance that is in line with wingtip substituent effects only. The relatively low activity of complex $\mathbf{2}$ indicates that the nickel complexes containing mesoionic ligands outperform the imidazolylidene analogue. Performing the reaction in the presence of simple nickel chloride as precatalyst did not lead to any detectable conversion (entry 5), suggesting an essential role of the carbene ligand for enabling catalytic activity.

Table 2. Hydrosilylation of 4-methylbenzaldhehyde with complexes 1a-c, . $^{\text {a }}$

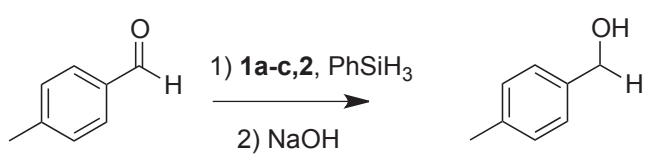

\begin{tabular}{|l|l|l|l|l|l|}
\hline entry & {$[\mathbf{N i}]$} & $\begin{array}{l}\text { time } \\
{[\mathbf{m i n}]}\end{array}$ & $\begin{array}{l}\mathbf{c o n v} \\
{[\mathbf{\%}]^{\mathbf{b}}}\end{array}$ & $\begin{array}{l}\mathbf{y i e l d} \\
{[\mathbf{\%}]^{\mathbf{c}}}\end{array}$ & $\mathbf{k}\left[\mathbf{h}^{-\mathbf{1}}\right]$ \\
\hline $\mathbf{1 a}$ & 120 & 98 & 94 & 2.4 \\
\hline 2 & $\mathbf{1 b}$ & 30 & 99 & 96 & 6.6 \\
\hline 3 & $\mathbf{1 c}$ & 60 & 98 & 94 & 3.6 \\
\hline 4 & $\mathbf{2}$ & 180 & 97 & 95 & 1.2 \\
\hline 5 & $\mathbf{N i C l}$ & 360 & $<1$ & & \\
\hline
\end{tabular}

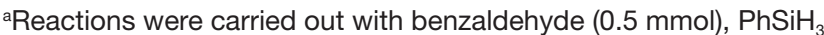
(0.6 mmol) and Ni complex (2 mol\%) in 1,2-dichloroethane $(0.4 \mathrm{~mL})$ with $\mathrm{C}_{6} \mathrm{Me}_{6}(0.05 \mathrm{mmol})$ as internal standard at $40^{\circ} \mathrm{C}$; ${ }^{\mathrm{b}} \mathrm{Conversion}$ determined by $1 \mathrm{H}$ NMR spectroscopy; ' $y$ ield determined by $1 \mathrm{H}$ NMR spectroscopy after treatment with $\mathrm{NaOH}(1 \mathrm{M})$ in $\mathrm{MeOH}$.

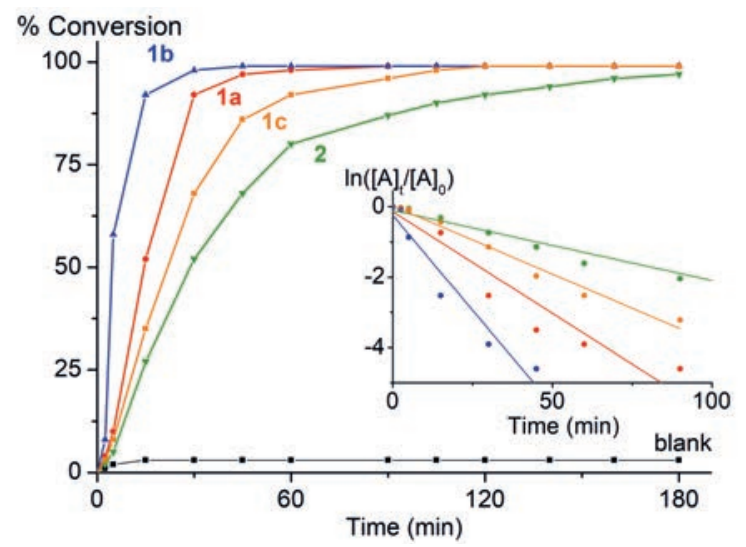

Fig. 2. Hydrosilylation of 4-methylbenzaldehyde with complexes 1a-c and 2. Inset: linear correlation of the time (min) with $\left[\ln \left([A]_{t} /[A]_{0}\right)\right]$ for each catalyst, $\left[\ln \left([\mathrm{A}]_{\mathrm{t}} /[\mathrm{A}]_{0}\right)\right]=-\mathrm{k}$ time, $\mathrm{R}^{2}=0.99$ (green line), 0.98 (orange line), 0.93 (blue line) and 0.92 (red line).

\subsection{Substrate Scope}

The scope of this catalytic hydrosilylation system was investigated by using the most active nickel complex, $\mathbf{1 b}$, and a variety of functionalised benzaldehydes. These studies revealed a high tolerance of the nickel catalyst towards various functional groups including halides, ethers, and amines (Fig. 3, Table 3). Electronrich benzaldehydes with substituents such as $-\mathrm{NMe}_{2},-\mathrm{OMe}$, and $-\mathrm{Me}$, as well as electron-poor ones with substituents such as $-\mathrm{F}$, $-\mathrm{Br}$, and $-\mathrm{CF}_{3}$, are converted completely within 7-180 min (entries 1-7). 


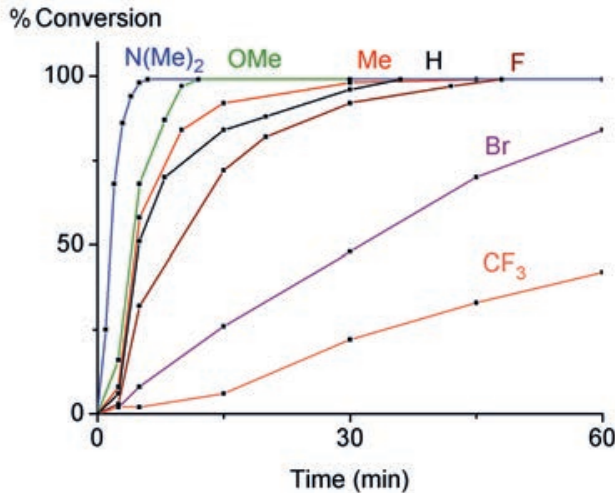

Fig. 3. Conversion profile for the hydrosilylation of different 4-substituted benzaldehydes with complex $\mathbf{1 b}$.

Table 3. Substrate scope for hydrosilylation with complex $\mathbf{1 b} .^{a}$

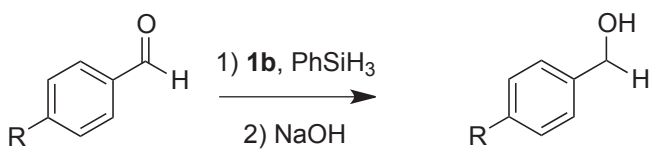

\begin{tabular}{|l|l|l|l|l|l|l|}
\hline entry & R-PhCHO & $\begin{array}{l}\text { time } \\
{[\mathbf{m i n}]}\end{array}$ & $\begin{array}{l}\mathbf{c o n v} \\
{[\mathbf{\%}]^{\mathbf{b}}}\end{array}$ & $\begin{array}{l}\text { yield } \\
{[\mathbf{\%}]^{\mathbf{c}}}\end{array}$ & $\sigma_{\mathbf{p}}$ & $\begin{array}{l}\text { TOF } \\
{\left[\mathbf{h}^{-1}\right]}\end{array}$ \\
\hline 1 & $4-\mathrm{NMe} 2$ & 6 & 99 & 95 & -0.83 & 730 \\
\hline 2 & $4-\mathrm{OMe}$ & 12 & 98 & 95 & -0.27 & 340 \\
\hline 3 & $4-\mathrm{Me}$ & 30 & 99 & 96 & -0.17 & 210 \\
\hline 4 & $4-\mathrm{H}$ & 36 & 97 & 95 & 0.00 & 150 \\
\hline 5 & $4-\mathrm{F}$ & 48 & 98 & 93 & 0.06 & 95 \\
\hline 6 & $4-\mathrm{Br}$ & 120 & 96 & 92 & 0.23 & 32 \\
\hline 7 & $4-\mathrm{CF3}$ & 180 & 98 & 92 & 0.54 & 6 \\
\hline 8 & $4-\mathrm{NO} 2$ & 180 & 13 & n.d. & 0.78 & n.d. \\
\hline
\end{tabular}

aReactions were carried out with benzaldehyde $(0.5 \mathrm{mmol}), \mathrm{PhSiH}_{3}$ (0.6 mmol) and complex $1 \mathbf{b}(2 \mathrm{~mol} \%)$ in 1,2-dichloroethane $(0.4 \mathrm{~mL})$ with $\mathrm{C}_{6} \mathrm{Me}_{6}(0.05 \mathrm{mmol})$ as internal standard at $40{ }^{\circ} \mathrm{C}$; bonversion

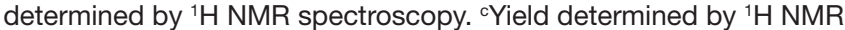
spectroscopy after treatment with $\mathrm{NaOH}(1 \mathrm{M})$ in $\mathrm{MeOH}$; n.d. = not determined.

Comparison of the reaction rates as $\mathrm{TOF}_{50}$ values with the Hammett parameter $\sigma_{p}$ shows an inverse correlation, with a lower Hammett parameter inducing faster turnover (Fig. 4). The correlation is satisfactory $\left(\mathrm{R}^{2}=0.98\right)$ and the considerable slope suggests a strong influence of the substituent's electronic properties on the reaction rate, which provides a rationale also for the very low conversion of nitrobenzaldehyde (Table 3 , entry 8 ). The inverse correlation between the Hammett parameter $\left(\sigma_{0}\right)$ and the turnover frequency indicates that positive charge is built up in the transition state. This observation is reminiscent of related carbene $\mathrm{Cp}$ nickel complexes and consistent with a turnover-limiting step that involves a hypervalent Si centre. ${ }^{[10]}$ Notably, acetophenone is not a suitable substrate for hydrosilylation with nickel complex $\mathbf{1 b}$ and essentially no conversion was observed even after $3 \mathrm{~h}$. The low activity of these complexes toward ketone hydrosilylation indicates a clear selectivity for aldehydes $v s$ ketones, which may be attractive in multifunctional substrates.

The catalytic potential of complex $\mathbf{1 b}$ was further investigated by variation of the catalyst loading in order to identify maximum

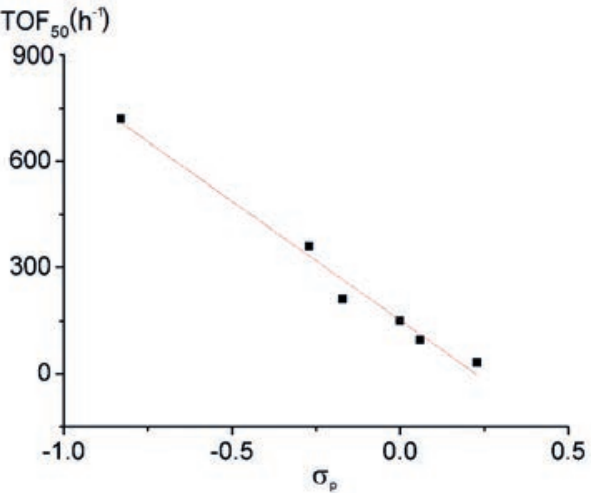

Fig. 4. Linear correlation of the Hammett parameter $\left(\sigma_{\mathrm{p}}\right)$ with turnover frequency at $50 \%$ conversion $\left(\mathrm{TOF}_{50}\right), \mathrm{TOF}_{50}=-488 \sigma_{\mathrm{p}}+197, \mathrm{R}^{2}=0.98$.

turnover numbers and frequencies of hydrosilylation using 4-anisaldehyde as the substrate. When using $2 \mathrm{~mol} \%$ of the catalyst precursor $\mathbf{1 b}$, the reaction is completed at $40{ }^{\circ} \mathrm{C}$ within $12 \mathrm{~min}$ (Table 4 , entry 1 ). This reactivity is three times faster when compared to runs using unsubstituted benzaldehyde as substrate (Table 3, entry 4). Quantitative formation of the product alcohol was also observed upon reducing the loading of complex $\mathbf{1 b}$ to 1 and $0.5 \mathrm{~mol} \%$, although reaction times were slightly longer to reach completion under these conditions (14 and $18 \mathrm{~min}$, respectively, entries 2 and 3 ). The reaction time is considerably shortened when the reaction temperature was increased to $60^{\circ} \mathrm{C}$, affording full conversion within 6 min with 2 mol\% loading of complex $\mathbf{1 b}$ (entry 4). Successively decreasing of the precatalyst to $0.02 \mathrm{~mol} \%$ does not compromise the yield of the reaction (entries 5-10). Full conversion at this low loading implies turnover numbers as high as 5,000, and maximum turnover frequencies of $27,000 \mathrm{~h}^{-1}$ (entry $10)$. When the loading of complex $\mathbf{1 b}$ was lowered even further to $0.01 \mathrm{~mol} \%$, conversions were incomplete even when the reaction was run for extended periods of time, yet these conditions allowed to determine the maximum turnover number TON $=7,400(60$ min, 63\%; entry 11). In the absence of nickel complex $\mathbf{1 b}$ no conversion was detected also at these slightly elevated temperatures (entry 12).

The $\mathrm{TOF}_{\max }$ values accomplished with complex $\mathbf{1 b}$ are higher than other known nickel-based hydrosilylation catalyst with ${ }^{[10]}$ or without a NHC ligand, ${ }^{[1,12]}$ and similar to those of the best-performing iron complexes, ${ }^{[13]}$ yet about two-times lower when compared to the best-performing manganese-based catalyst. [14] The high catalytic performance of $\mathbf{1 b}$ in terms of turnover numbers and frequencies suggests a marked influence imparted by chelation of the triazolylidene ligand when bound to nickel. Its key role is confirmed when comparing complex $\mathbf{3}$ as the best nickel catalyst reported so far with the Ni-O(NHC) system $\mathbf{1 b}$ (Fig. 5). Under the same catalytic conditions, the $O$-chelated nickel complex $\mathbf{1 b}$ outperforms the $\mathrm{N}$-chelated system 3 and reaches higher TON $(7,400$

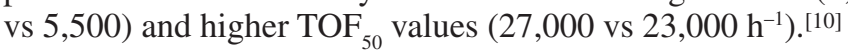

\subsection{Stoichiometric Experiments}

In order to better understand the observed activities of catalyst $\mathbf{1 b}$ and more generally the potential role of oxygen chelation during hydrosilylation, a set of stoichiometric experiments was performed. Adding a slight excess (1.2 equiv) of phenylsilane to complex $\mathbf{1 b}$ in a $\mathrm{CD}_{2} \mathrm{Cl}_{2}$ solution containing $\mathrm{SiMe}_{4}$ as an internal standard resulted in an immediate change in colour of the solution and different sets of new signals appeared in the ${ }^{1} \mathrm{H}$ NMR spectrum, suggesting the formation of new species. The resonances of complex $\mathbf{1 b}$ disappeared and no triazolium salt formation was detected, while two singlets appeared in the hydride region at $\delta_{\mathrm{H}}$ $=-7.19$ and $-8.21 \mathrm{ppm}$ in a 1:1 relative ratio and accounting for 
Table 4. Hydrosilylation of 4 -anisaldehyde with complexes $\mathbf{1 b} .^{\text {a }}$

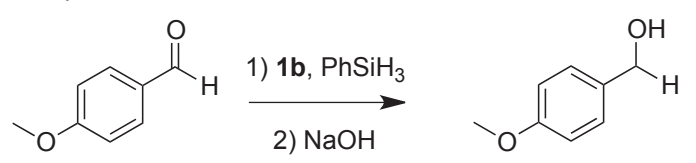

\begin{tabular}{|c|c|c|c|c|c|c|c|}
\hline entry & $\mathrm{mol} \% \mathbf{1 b}$ & $\mathbf{T}\left[{ }^{\circ} \mathbf{C}\right]$ & time [min] & $\operatorname{conv}[\%]^{b}$ & yield [\%] ${ }^{\mathrm{c}}$ & TON & $\operatorname{TOF}_{50}\left[h^{-1}\right]$ \\
\hline 1 & 2 & 40 & 12 & 99 & 96 & 48 & 340 \\
\hline 2 & 1 & 40 & 14 & 98 & 94 & 96 & 460 \\
\hline 3 & 0.5 & 40 & 18 & 99 & 95 & 192 & 636 \\
\hline 4 & 2 & 60 & 6 & 99 & 96 & 48 & 568 \\
\hline 5 & 1 & 60 & 6 & 99 & 95 & 96 & 960 \\
\hline 6 & 0.5 & 60 & 8 & 98 & 96 & 192 & 2,600 \\
\hline 7 & 0.25 & 60 & 16 & 99 & 93 & 384 & 2,200 \\
\hline 8 & 0.1 & 60 & 20 & 99 & 96 & 892 & 3,800 \\
\hline 9 & 0.05 & 60 & 20 & 99 & 94 & 1,850 & 14,500 \\
\hline 10 & 0.02 & 60 & 20 & 93 & 89 & 4,500 & 27,000 \\
\hline 11 & 0.01 & 60 & 60 & 74 & 63 & 7,400 & 6,500 \\
\hline $12^{\mathrm{d}}$ & 0 & 60 & 120 & $<1$ & & & \\
\hline
\end{tabular}

aReactions were carried out with 4-anisaldehyde $(0.5 \mathrm{mmol}), \mathrm{PhSiH}_{3}(0.6 \mathrm{mmol})$ and complex 1b in 1,2-dichloroethane $(0.4 \mathrm{~mL})$ with $\mathrm{C}_{6} \mathrm{Me}_{6}$ $(0.05 \mathrm{mmol})$ as internal standard; ${ }^{\mathrm{b}}$ conversion determined by ${ }^{1} \mathrm{H}$ NMR spectroscopy; ${ }^{\mathrm{C}}$ yield determined by ${ }^{1} \mathrm{H}$ NMR spectroscopy after treatment with $\mathrm{NaOH}(1 \mathrm{M})$ in $\mathrm{MeOH}$; d In absence of any nickel complex.

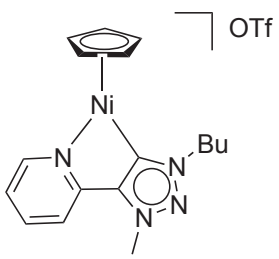

3

TOF $_{50}=23,000 \mathrm{~h}^{-1}$

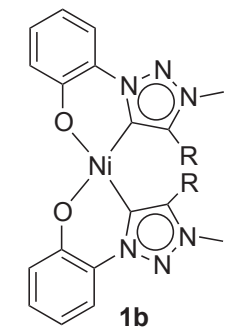

TOF $_{50}=27,000 \mathrm{~h}^{-1}$
Fig. 5. Best performing Ni NHC supported catalysts known for the hydrosilylation of aldehydes. ${ }^{[10]}$

almost $80 \%$ when compared to the internal standard. These observations suggest the formation of two metal hydride species. The ${ }^{13} \mathrm{C}$ NMR signals were less clear, yet, two new resonances at 152 and $154 \mathrm{ppm}$ were observed and attributed to phenolate $\mathrm{C}-\mathrm{O}$ groups. These resonances are shifted upfield compared to the $\mathrm{C}-\mathrm{O}$ resonance in $\mathbf{1 b}\left(\delta_{\mathrm{C}-\mathrm{O}}=160 \mathrm{ppm}\right)$ and compatible with the values of free phenol C-O groups that are not metal-coordinated, as for example in the triazolium ligand precursor $\left(\delta_{\mathrm{C}-\mathrm{OH}}=150\right.$ $\mathrm{ppm})$. The ${ }^{29} \mathrm{Si}$ NMR spectrum supports the formation of two new species as two new signals appeared in the -25 to $-30 \mathrm{ppm}$ region (Fig. 6). Their chemical shift is substantially downfield from the signal of $\mathrm{PhSiH}_{3}\left(\delta_{\mathrm{Si}}=-60\right)$ and indicative of a more electrophilic silicon nucleus. All these data are consistent with cleavage of the $\mathrm{Ni}-\mathrm{O}$ bond and concomitant formation of the two isomers of a nickel-hydride complex containing a phenylsilylether, cis-5 and trans -5 as a result of the addition of a $\mathrm{Si}-\mathrm{H}$ bond across the $\mathrm{Ni}-\mathrm{O}$ bond (Scheme 1). ${ }^{[15]}$

Interestingly, an identical experiment using stoichiometric amounts of $\mathrm{Et}_{3} \mathrm{SiH}$ instead of $\mathrm{PhSiH}_{3}$ did not induce any spec-

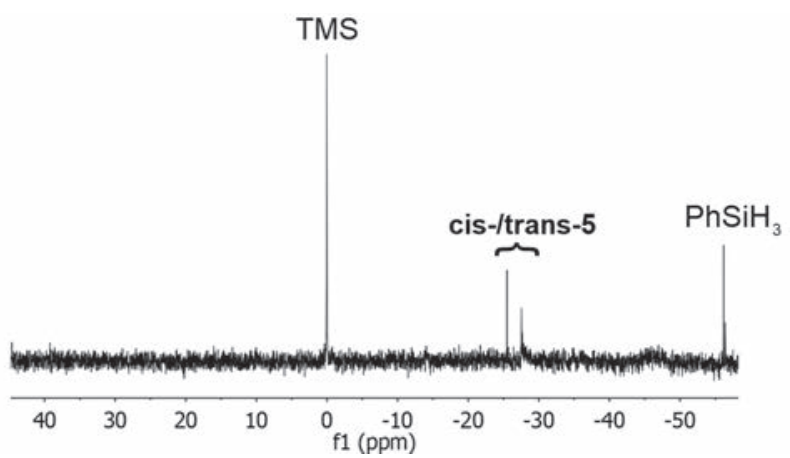

Fig. 6. ${ }^{29} \mathrm{Si}$ NMR spectrum of a solution of complex $\mathbf{1 b}$ after the addition of $\mathrm{PhSiH}_{3}$ (1.2 equiv) and TMS used as internal standard.

troscopic changes of complex $\mathbf{1 b}$ according to ${ }^{1} \mathrm{H}$ and ${ }^{29} \mathrm{Si} \mathrm{NMR}$ spectroscopy. Since $\mathrm{Et}_{3} \mathrm{SiH}$ is also catalytically inactive, these data suggesting that the silane addition and formation of the silylether is inhibited, suggesting that this step is essential for catalyst activation. These observations therefore lend support to a met-

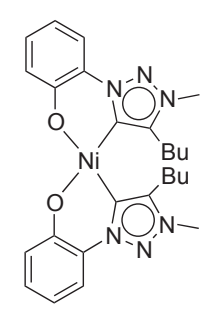

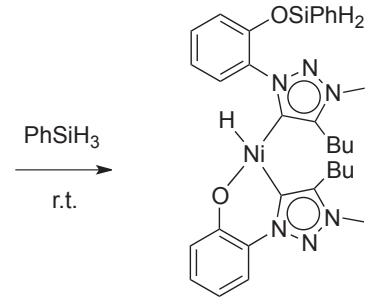

cis-5

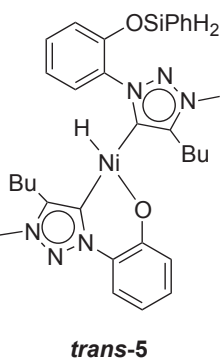

trans-5
Scheme 1. Proposed Ni-O bond cleavage and formation of cis-5 and trans-5 from reaction of complex $\mathbf{1 b}$ with phenylsilane. 
al-ligand cooperative mechanism for the activation of the $\mathrm{Si}-\mathrm{H}$ bond and a beneficial role of the anionic oxygen functionality in hydrosilylation catalysis.

Several different mechanisms have been put forward for the hydrosilylation of $\mathrm{C}=\mathrm{C}$ and $\mathrm{C}=\mathrm{O}$ bonds over the years. ${ }^{[16-19]}$ Based on our observations, a tentative mechanism is proposed (Scheme 2), involving catalyst activation via $\mathrm{Ni}-\mathrm{O}$ bond cleavage to form the hydride species $\mathbf{5}$. This step may be under rigorous steric control due to the bulkiness of the carbene ligand as well as the shielding of the silicon nucleus, thus providing a rationale for the loss in activity when changing the hydrosilylation agent from $\mathrm{PhSiH}_{3}$ to $\mathrm{Ph}_{2} \mathrm{SiH}_{2}$ or $\mathrm{Et}_{3} \mathrm{SiH}$. Different pathways are conceivable from this hydride species $\mathbf{5}$. We propose that the aldehyde substrate is coordinating to the nickel hydride $\mathbf{5}$ to form the pentacoordinate $\mathrm{Ni}$ adduct $\mathbf{A}$. Subsequent activation of the carbonyl unit produces transition state $\mathbf{B}$ comprised of a carbon with a strong $\delta^{+}$character, which is in line with the inverse correlation of the Hammett parameter and the reaction rate, as well as the dependence of catalytic activity on the electron density at the nickel centre. The higher the electron density at the metal centre is, the more reactive the hydride. Completing the migratory insertion step affords the alkoxide nickel intermediate $\mathbf{C}$, which is presumed to react with phenylsilane via heterolytic $\mathrm{Ni}-\mathrm{O}$ bond cleavage to conclude the cycle and release the product with concomitant regeneration of the nickel hydride 5. An alternative mechanism consistent with our data involves the formation of a silylene in analogy to the catalytic systems developed by Tilley and coworkers. ${ }^{[20]}$

\section{Conclusions}

Nickel(II) complexes with C,O-bidentate chelating mesoionic carbene ligands display remarkable activity in the hydrosilylation of $\mathrm{C}=\mathrm{O}$ bonds. Complexes supported by mesoionic ligands outperformed non-mesoionic analogues and can be rationally tailored to reach very high turnover frequencies and turnover num- bers in the thousands, indicating a reliable control of the catalytic nickel centre through ligand modification. The catalytic system is selective towards aldehyde reduction and tolerant to electron-rich and -poor benzaldehydes. These results provide useful guidelines for installing $O$-containing functional groups to promote ligand cooperativity in catalytic systems based on first-row transition metals. Moreover, this work demonstrates that appropriate ligand design provides a powerful methodology for approaching the catalytic activity of noble metal catalysts by using Earth-abundant metal complexes.

\section{Acknowledgements}

We gratefully acknowledge generous financial support from the European Research Council (CoG 615653) and the European Union Marie Sklodowska-Curie Initial Training NoNoMeCat (675020-MSCAITN-2015-ETN)

Received: March 30, 2020

[1] a) G. C. Vougioukalakis, R. H. Grubbs, Chem. Rev. 2010, 110, 1746; b) D. A Colby, A. S. Tsai, R. G. Bergman, J. A. Ellman, Acc. Chem. Res. 2012, 45, 814; c) J. F. Hartwig, Acc. Chem. Res. 2008, 41, 1534.

[2] a) W. A Herrmann, Angew. Chem. Int. Ed. 2002, 41, 1290; b) F. E. Hahn, M. C. Jahnke, Angew. Chem. Int. Ed. 2008, 47, 3112 .

[3] a) E. Peris, Chem. Rev 2018, 118, 9988; b) S. T. Liddle, I. S. Edworthy, P. L. Arnold, Chem. Soc. Rev. 2007, 36, 1732; c) C. Valente, S. Calimsiz, K. H. Hoi, D. Mallik, M. Sayah, M. G. Organ, Angew. Chem. Int. Ed. 2012, 51, $3314-3332$.

[4] S. Hameury, P. de Frèmont, P. Braunstein Chem. Soc. Rev. 2017, 46, 632.

[5] O. Kühl, Chem. Soc. Rev. 2007, 36, 592.

[6] R. M. Bullock, 'Catalysis without precious metals', 2011, Wiley-VCH, Weinheim, Germany.

[7] Y. Wei, A. Petronilho, H. Mueller-Bunz, M. Albrecht, Organometallics 2014, 33, 5834 .

[8] Y. N. Kotovshchikov, G. V. Latyshev, M. A. Navasardyan, D. A. Erzunov, I. P. Beletskaya, N. V. Lukashev, Org. Lett. 2018, 20, 4467.

[9] S. Bertini, F. Gloaguen, M. Rahaman, S. Huemann, P. Broekmann, P. Schollhammer, M. Albrecht, submitted.

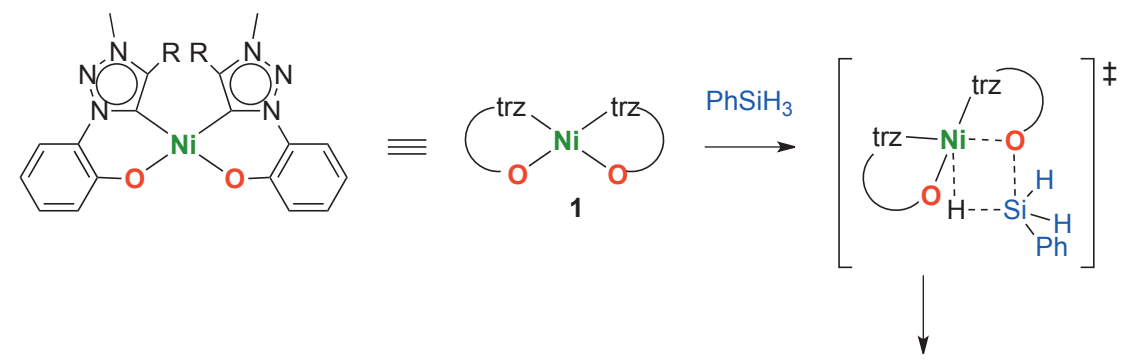

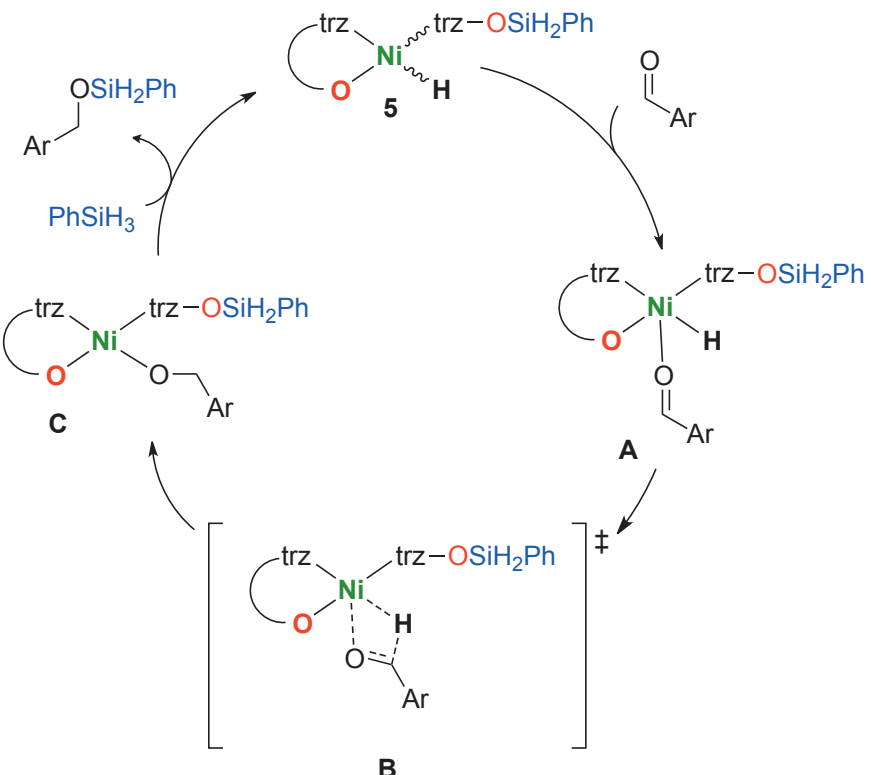

Scheme 2. Proposed mechanistic cycle for hydrosilylation of $\mathrm{C}=\mathrm{O}$ with complex 1. 
[10] Y. Wei, S.-X. Liu, H. Mueller-Bunz, M. Albrecht, ACS Catal. 2016, 6, 8192.

[11] L. Postigo, B. Royo, Adv. Synth. Catal. 2012, 354, 2613.

[12] a) B. Chatterjee, C. Gunanathan, Chem. Commun. 2014, 50, 888; b) S. N. MacMillan, W. Hill Harman, J. C. Peters, Chem. Sci. 2014, 5, 590.

[13] A. J. Ruddy, C. M. Kelly, S. M. Crawford, C. A. Wheaton, O. L. Sydora, B L. Small, M. Stradiotto, L. Turculet, Organometallics 2013, 32, 5581.

[14] a) T. K. Mukhopadhyay, M. Flores, T. L. Groy, R. J. Trovitch, J. Am. Chem. Soc. 2014, 136, 882; b) C. Ghosh, T. K. Mukhopadhyay, M. Flores, T. L. Groy, R. J. Trovitch, Inorg. Chem. 2015, 54, 10398.

[15] T. Stahl, P. Hrobarik, C. D. F. Konigs, Y. Ohki, K. Tatsumi, S. Kemper, M. Kaupp, H. F. T. Klare, M. Oestreich, Chem. Sci. 2015, 6, 4324.

[16] L. Wang, H. Sun, X. Li, Organometallics 2015, 34, 5175.

[17] B. H. Lipshutz, B. A. Frieman, Angew. Chem., Int. Ed. 2005, 44, 6345.

[18] K. Revunova, G. I. Nikonov, Chem. Eur. J. 2014, $20,839$.

[19] L. Monsigny, P. Thuéry, J.-C. Berthet, T. Cantat, ACS Catalysis 2019, 9 , 9025 .

[20] a) P. B. Glaser, T. D. Tilley, J. Am. Chem. Soc. 2003 125, 13640; b) R. Waterman, P. G. Hayes, T. D. Tilley, Acc. Chem. Res. 2007, 40, 712.

\section{License and Terms}

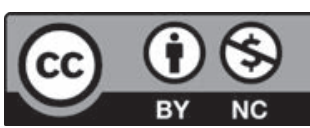

This is an Open Access article under the terms of the Creative Commons Attribution License CC BY_NC 4.0. The material may not be used for commercial purposes.

The license is subject to the CHIMIA terms and conditions: (http:// chimia.ch/component/sppagebuilder/?view=page \&id=12).

The definitive version of this article is the electronic one that can be found at doi:10.2533/chimia.2020.483. 